\title{
Thyroid Dysfunction Associated with Administration of the Long-Acting Gonadotropin-Releasing Hormone Agonist
}

\author{
Eun Jin Han, Ha Do Song, Ji Hoon Yang, So Young Park, Sung Hoon Kim, Hyun Koo Yoon, Chang Hoon Yim \\ Department of Internal Medicine, Cheil General Hospital \& Women's Healthcare Center, Kwandong University College of \\ Medicine, Seoul, Korea
}

Gonadotropin-releasing hormone $(\mathrm{GnRH})$ agonist has been used in the treatment of a wide variety of sex-hormone-related diseases, as the administration of GnRH agonist can alter the secretion of gonadotropin and sex hormones. Recently, we found that the long-acting GnRH agonist aggravated hyperthyroidism and induced painless thyroiditis. This is the first report to demonstrate the association of thyroid dysfunction with GnRH agonist injection in Korea. Here, we report three cases and emphasize the clinical importance of this aggravating factor in autoimmune thyroid disease.

Keywords: Gonadotropin-releasing hormone agonist; Graves' disease; Painless thyroiditis

\section{INTRODUCTION}

Currently, gonadotropin-releasing hormone $(\mathrm{GnRH})$ agonist is commonly used for various sex-hormone-related diseases (uterine myoma, endometriosis, precocious puberty, dysfunctional uterine bleeding, assisted reproductive technology, etc.). The main mechanism of action is the change in the secretion of gonadotropin and sex hormones. In the initial administration, they are associated with an increase in estrogen due to the increase of follicle stimulating hormone and luteinizing hormone, and with the prolonged administration, they are associated with estrogen reduction due to desensitization by down-regulation of GnRH receptor [1]. The main side effects of these drugs are hypoestrogenism-induced symptoms, such as facial flushing, headache, depression, anxiety, insomnia, colpoxerosis, and osteoporosis. Meanwhile, the autoimmune

Received: 8 August 2012, Accepted: 23 September 2012

Corresponding author: Chang Hoon Yim

Department of Internal Medicine, Cheil General Hospital \& Women's

Healthcare Center, Kwandong University College of Medicine, 17 Seoae-ro

1-gil, Jung-gu, Seoul 100-380, Korea

Tel: $+82-2-2000-4719$, Fax: $+82-2-2000-7147$,

E-mail: changhoon.yim@cgh.co.kr thyroid diseases, including Graves' disease and painless thyroiditis, are affected by various genetic and environmental factors [2]. Of environmental factors, the typical example that can infer from the relation between sex hormones and thyroid immune tolerance and autoimmunity is postpartum thyroid dysfunction [3-5]. In addition, some case reports have shown that $\mathrm{GnRH}$ agonist-induced relative estrogen reduction may cause autoimmune thyroid disease by immune rebound [6-10], but there have been no reports in the Korean literature.

Here, we report three cases of thyroid dysfunction related to the prolonged administration of $\mathrm{GnRH}$ agonist.

\section{CASE REPORTS}

\section{Case 1}

A 30-year-old female came to the Department of Obstetrics

This is an Open Access article distributed under the terms of the Creative Commons Attribution Non-Commercial License (http://creativecommons.org/ licenses/by-nc/3.0/) which permits unrestricted non-commercial use, distribution, and reproduction in any medium, provided the original work is properly cited. 
and Gynecology at Cheil General Hospital \& Women's Healthcare Center with dysmenorrhea 3 months ago. She received subcutaneous injections of leuprorelin acetate $3.75 \mathrm{mg}$ per month, three times in all, with a diagnosis of uterine myoma and endometriosis. She was examined for thyroid function prior to laparoscopic surgery 1 week ago and she was sent to the Department of Internal Medicine because of thyroid dysfunction. Her blood pressure was $116 / 76 \mathrm{~mm} \mathrm{Hg}$, pulse was 60 per minute, and body mass index (BMI) was $21.9 \mathrm{~kg} / \mathrm{m}^{2}$ $160 \mathrm{~cm}, 56 \mathrm{~kg}$. She had no past medical history, but her mother had previously taken medication for hypothyroidism.

She had no special symptoms, such as fatigue, weight fluctuation, edema, and gastrointestinal problems. However, she complained of recently occurred sweating and facial flushing. On physical examination, she had slightly diffuse thyroid enlargement and the electrocardiography (ECG) was normal.

Serum free T4 (fT4, $6.9 \mathrm{pmol} / \mathrm{L}$ ) was decreased and thyroid stimulating hormone (TSH, $154.4 \mu \mathrm{U} / \mathrm{mL}$ ) was elevated. Antithyroglobulin antibody (anti-TG Ab, $100 \mathrm{U} / \mathrm{mL}$ ) and anti thyroid peroxidase antibody (anti-TPO Ab, $58 \mathrm{U} / \mathrm{mL}$ ) were both positive, whereas TSH binding inhibitory immunoglobulin (TBII, 4\%) was negative. Thus, she started thyroid hormone replacement therapy (levothyroxine $0.1 \mathrm{mg}$ ) with a diagnosis of hypothyroidism.

One month later, her thyroid function was normalized (fT4, $21.9 \mathrm{pmol} / \mathrm{L}$; TSH, $2.91 \mu \mathrm{U} / \mathrm{mL}$ ) and 2 months later, she underwent laparoscopic myomectomy. After the operation, she received injections of leuprorelin acetate three more times; thereafter, her thyroid function was maintained within the normal range. She is currently maintaining levothyroxine $0.1 \mathrm{mg}$ under serial assessment by the Department of Internal Medicine (Table 1).

\section{Case 2}

A 35-year-old female came to the Department of Obstetrics and Gynecology at Cheil General Hospital \& Women's Healthcare Center with sterility 6 months ago. In the past medical history, she had been treated with medication for hyperthyroidism and had underwent surgery for endometriosis. She had received subcutaneous injections of leuprorelin acetate of 3.75 mg per month, three times in all, as a pretreatment for in vitro fertilization from 2 months ago. Since she had a past history of hyperthyroidism, she was refered to the Department of Internal Medicine for further evaluation.

Her blood pressure was $118 / 79 \mathrm{~mm} \mathrm{Hg}$, pulse was 79 per minute, and BMI was $18.6 \mathrm{~kg} / \mathrm{m}^{2}(159 \mathrm{~cm} / 47 \mathrm{~kg})$. She had been diagnosed with hyperthyroidism a decade ago and had taken methimazole 10 to $2.5 \mathrm{mg}$ until 3 months before she came to our hospital because her thyroid function was normalized. She also underwent surgery for endometriosis at another hospital 1 year ago. Nothing was noteworthy in her family history.

She complained of sweating, heat sensation intolerance, and facial flushing. On physical examination, she had slightly diffuse thyroid enlargement and the ECG was normal.

Serum T3 (120.6 ng/dL), fT4 (21.8 pmol/L), and TSH (0.51 $\mu \mathrm{U} / \mathrm{mL})$ were all whinin the normal range, but anti-TG Ab (13 $\mathrm{U} / \mathrm{mL})$, anti-TPO $\mathrm{Ab}(>100 \mathrm{U} / \mathrm{mL})$, and TBII (22\%) were all positive. Thus, further observation was required.

One month later, she complained of palpitation and fatigue, while T3 (259.5 ng/dL) and fT4 (60.6 pmol/L) were elevated, TSH $(<0.01 \mu \mathrm{U} / \mathrm{mL})$ was suppressed, and anti-TG Ab (17 U/ $\mathrm{mL})$, anti-TPO $\mathrm{Ab}(>100 \mathrm{U} / \mathrm{mL})$, and TBII was elevated to $27 \%$. Thus, she was diagnosed with hyperthyroidism and started taking methimazole $10 \mathrm{mg}$. Two months later, T3 (304.0 $\mathrm{ng} / \mathrm{dL})$, fT4 (57.0 pmol/L), TSH $(<0.01 \mu \mathrm{U} / \mathrm{mL})$, and TBII

\begin{tabular}{|c|c|c|c|c|}
\hline & \multicolumn{4}{|c|}{ Time elapsed after administration of GnRH agonist, mo } \\
\hline & 2 & $3^{\mathrm{a}}$ & $6^{\mathrm{a}}$ & $9^{\mathrm{a}}$ \\
\hline $\mathrm{T} 3(80-200 \mathrm{ng} / \mathrm{dL})$ & 91 & 126.7 & 91.6 & 100.6 \\
\hline fT4 (10-28 pmol/L) & 6.9 & 21.9 & 16.9 & 18.5 \\
\hline $\mathrm{TSH}(0.2-5.6 \mu \mathrm{U} / \mathrm{mL})$ & 154.4 & 2.91 & 5.55 & 3.27 \\
\hline Antithyroglobulin $\mathrm{Ab}(0-0.3 \mathrm{U} / \mathrm{mL})$ & 100 & 31 & 24 & 20 \\
\hline Antithyroid peroxidase $\mathrm{Ab}(0-0.3 \mathrm{U} / \mathrm{mL})$ & 58 & $>100$ & 44 & 10 \\
\hline TBII $(0 \%-15 \%)$ & 4 & 6 & 10 & 4 \\
\hline
\end{tabular}

GnRH, gonadotropin-releasing hormone; fT4, free T4; TSH, thyroid stimulating hormone; Ab, antibody; TBII, thyrotropin binding inhibitory immunoglobulin.

${ }^{a}$ Levothyroxine $0.1 \mathrm{mg} /$ day. 
Table 2. Aggravated Hyperthyroidism during Treatment with Gonadotropin-Releasing Hormone Agonist, Leuprorelin Acetate

\begin{tabular}{lcrrrr}
\hline & \multicolumn{5}{c}{$\begin{array}{c}\text { Time elapsed after administration } \\
\text { of GnRH agonist, mo }\end{array}$} \\
\cline { 2 - 6 } & -3 & 2 & 3 & $4^{\mathrm{a}}$ & $5^{\mathrm{b}}$ \\
\hline T3 & 17.4 & 21.8 & 60.6 & 57.0 & 24.8 \\
fT4 & 2.53 & 0.51 & $<0.01$ & $<0.01$ & $<0.01$ \\
TSH & & 13 & 17 & 16 & 19 \\
Antithyroglobulin Ab & & $>100$ & $>100$ & $>100$ & $>100$ \\
Antithyroid peroxidase Ab & & 22 & 27 & 37 & 38 \\
TBII & & & & 304.0 & 104.8 \\
\hline
\end{tabular}

GnRH, gonadotropin-releasing hormone; fT4, free T4; TSH, thyroid stimulating hormone; $\mathrm{Ab}$, antibody; TBII, thyrotropin binding inhibitory immunoglobulin.

${ }^{\mathrm{a}}$ Methimazole $10 \mathrm{mg} / \mathrm{day}$; ${ }^{\mathrm{b}}$ Propylthiouracil $200 \mathrm{mg} /$ day.

was elevated to $37 \%$ and medication was changed to propylthiouracil $200 \mathrm{mg}$. Three months later, she is currently maintaining propylthiouracil $100 \mathrm{mg}$ under serial assessment by the Department of Internal Medicine (Table 2).

\section{Case 3}

A 24-year-old female came to the Department of Obstetrics and Gynecology at Cheil General Hospital \& Women's Healthcare Center with right lower abdominal pain 2 months ago and she underwent laparoscopic ovarian cystectomy. Subsequently, she had received subcutaneous injections of leuprorelin acetate of $3.75 \mathrm{mg}$ per month, twice in all. It was accidentally found by another hospital that she had thyroid dysfunction and thyroid enlargement verified by a sonogram 2 days ago. Thus, she was referred to the Department of Internal Medicine.

Her blood pressure was $111 / 67 \mathrm{~mm} \mathrm{Hg}$, pulse was 80 per minute, and BMI was $18.4 \mathrm{~kg} / \mathrm{m}^{2}(165 \mathrm{~cm} / 50 \mathrm{~kg})$. Nothing was noteworthy in her medical histoy or family history.

She complained of weight loss of $4 \mathrm{~kg}$ over 1 year, cold sensation intolerance, and facial flushing. On physical examination, she had diffuse thyroid enlargement and the ECG was normal.

Both serum T3 $(211.6 \mathrm{ng} / \mathrm{dL})$ and fT4 $(38.6 \mathrm{pmol} / \mathrm{L})$ were elevated and TSH $(<0.01 \mu \mathrm{U} / \mathrm{mL})$ was suppressed. Anti-TG $\mathrm{Ab}(17 \mathrm{U} / \mathrm{mL})$ and anti-TPO $\mathrm{Ab}(>100 \mathrm{U} / \mathrm{mL})$ were all positive and TBII was $4 \%$. Meanwhile, the reduction of thyroid uptake was discovered on technetium-99m thyroid scan. She was diagnosed with transient thyrotoxicosis and observed without treatment.
Table 3. Onset of Transient Thyrotoxicosis during Treatment with Gonadotropin-Releasing Hormone Agonist, Leuprorelin Acetate

\begin{tabular}{lrrrc}
\hline & \multicolumn{4}{c}{$\begin{array}{c}\text { Time elapsed after administration } \\
\text { of GnRH agonist, mo }\end{array}$} \\
\cline { 2 - 5 } & 1 & 2 & 3 & 5 \\
\hline T3 & 211.6 & 112.3 & 80.5 & 91.0 \\
fT4 & 38.6 & 14.3 & 9.1 & 11.5 \\
TSH & $<0.01$ & 0.01 & 9.81 & 2.33 \\
Antithyroglobulin Ab & 17 & 14 & 23 & 63 \\
Antithyroid peroxidase Ab & $>100$ & $>100$ & $>100$ & $>100$ \\
TBII & 4 & $<1$ & $<1$ & $<1$ \\
\hline
\end{tabular}

GnRH, gonadotropin-releasing hormone; fT4, free T4; TSH, thyroid stimulating hormone; $\mathrm{Ab}$, antibody; TBII, thyrotropin binding inhibitory immunoglobulin.

One month later, TSH $(0.01 \mu \mathrm{U} / \mathrm{mL})$ still had been suppressed, but both T3 (112.3 ng/dL) and fT4 (14.3 pmol/L) were normalized; thereafter, leuprorelin acetate was injected subcutaneously four more times. Two months later, fT4 (9.1 pmol/L) was decreased and TSH $(9.81 \mu \mathrm{U} / \mathrm{mL})$ was elevated without symptoms of hypothyroidism, and observation was continued. Four months later, both fT4 (11.5 pmol/L) and TSH $(2.33 \mu \mathrm{U} /$ $\mathrm{mL}$ ) were normalized and she is currently under serial assessment (Table 3).

\section{DISCUSSION}

The GnRH analogue is synthesized by the substitution of amino acids in GnRH. One of them, GnRH agonist has a strong affinity to the GnRH receptor with a long half-life; therefore, it has almost the same effect as when gonadotropin has been continuously exposed to GnRH. After the initial flare effect, hormones administered repeatedly reveal the paradoxical antagonistic effect by down-regulation and desensitization, resulting in a hypogonadotrophic hypogonadism state. Accordingly, this agonist has been used for various sex-hormone-related diseases, but it also has side effects inducing pseudomenopause state with long-term use.

Many environmental factors have been reported to induce autoimmune thyroid disease [2], and the fluctuation of sex hormones is one of the important factors of thyroid autoimmunity. Therefore, GnRH gonist-induced alteration in serum levels of gonadotropin and sex hormones may trigger thyroid autoimmunity [11].

The increase of estrogen inhibits the immune reaction of 
autoimmune disease, which can be explained by the spontaneous remission of autoimmune disease during pregnancy. On the other hand, the reduction of estrogen induces immune rebound, as in the aggravation of autoimmune disease during postpartum period. It is assumed that the GnRH agonist-derived relative estrogen reduction induced immune rebound and aggravated the preexisting subclinical or mild autoimmune thyroid disease $[3,4]$.

In relation to the use of leuprolide acetate, Kasayama et al. [6] published a report on transient thyrotoxicosis and hypothyroidism, Amino et al. [7] published a report on Graves' disease and painless thyroiditis, and Van Bon et al. [9] reported a case of transient thyrotoxicosis after using goserelin acetate in a hypothyroid patient, but nothing has been reported in the Korean literature. Furthermore, GnRH agonist-induced aggravation of autoimmune disease is not limited to thyroid disease and there is a case report that leuprolide acetate-associated lupus nephritis was also aggravated [12]. In the above three cases, we found hypothyroidism, hyperthyroidism, and both transient thyrotoxicosis and hypothyroidism respectively in sequence, and this indicates that there may be various kinds of thyroid dysfunction after $\mathrm{GnRH}$ agonist administration, like postpartum thyroid dysfunction.

Considering that there was a change in thyroid function at 1 to 3 months after subcutaneous injections of leuprorelin acetate in the above cases, we assume that the main mechanism of disease was caused by the hypoestrogenic state, rather than by the initial gonadotropin surge [6]. The findings resembled previous cases in which thyroid dysfunction began after 3 to 4 months [6-9]. Moreover, since most patients who had been treated with GnRH agonist complained of symptoms derived from hypoestrogenism, like sweating and facial flushing, this most likely rules out the possibility of thyroid dysfunction. In these cases, most patients also complained of sweating and facial flushing rather than typical symptoms of thyroid dysfunction. Under these circumstances, we think that thyroid function test and autoantibody test are needed in addition to medical examination by interview and physical examination.

The GnRH agonist itself has no influence on thyroid hormone or TSH for healthy women or endometriosis patients, but it has been reported that preexisting diseases appear to be aggravated in patients with subclinical or mild autoimmune disease [7]. Given that the present cases were positive for antiTG $\mathrm{Ab}$ and anti-TPO Ab, it is assumed that the treatment of prolonged GnRH agonist in the presence of subclinical autoimmune thyroid disease generated hypothyroidism, transient thyrotoxicosis and the aggravation of hyperthyroidism.

The above cases verified a possible association between the alteration of gonadotropin and sex hormones and thyroid dysfunction, and in the future, we suggest that clinicians pay attention to the thyroid state when starting the treatment of GnRH agonist for patients at risk of autoimmune thyroid disease. Likewise, it is very important to check the past history or family history of autoimmune diseases for all patients who will receive GnRH agonist treatment. It is also recommended that patients be examined for antithyroid $\mathrm{Ab}$ and thyroid function. However, the above cases are not sufficient to establish a cause-and-effect relationship and further study of the association between the GnRH agonist and autoimmune thyroid disease is needed.

In summary, GnRH agonist is currently used in the treatment of various sex-hormone-related diseases and the mechanism is associated with estrogen reduction from desensitization by down-regulation of GnRH receptor caused by the prolonged administration. However, the GnRH agonist-derived relative estrogen reduction may induce immune rebound, resulting in autoimmune thyroid disease. A few cases have been reported, but none have been reported in the Korean literature. Therefore, in the present case report, we describe three cases of thyroid dysfunction after the use of GnRH agonist. In the above cases, the administration of $\mathrm{GnRH}$ agonist showed the possibility of thyroid dysfunction, and therefore attention should be paid to the thyroid in patients vulnerable to autoimmune thyroid disease when beginning the treatement of GnRH agonist.

\section{CONFLICTS OF INTEREST}

No potential conflict of interest relevant to this article was reported.

\section{REFERENCES}

1. Tzafettas JM. Current and potential application of GnRH agonists in gynecologic practice. Ann N Y Acad Sci 2000; 900:435-43.

2. Tomer Y, Huber A. The etiology of autoimmune thyroid disease: a story of genes and environment. J Autoimmun 2009;32:231-9.

3. Amino N, Tada H, Hidaka Y, Izumi Y. Postpartum autoimmune thyroid syndrome. Endocr J 2000;47:645-55.

4. Amino N, Tada H, Hidaka Y. Postpartum autoimmune thyroid syndrome: a model of aggravation of autoimmune dis- 
ease. Thyroid 1999;9:705-13.

5. Lichiardopol C, Mota M. The thyroid and autoimmunity. Rom J Intern Med 2009;47:207-15.

6. Kasayama S, Miyake S, Samejima Y. Transient thyrotoxicosis and hypothyroidism following administration of the GnRH agonist leuprolide acetate. Endocr J 2000;47:783-5.

7. Amino N, Hidaka Y, Takano T, Tatsumi KI, Izumi Y, Nakata Y. Possible induction of Graves' disease and painless thyroiditis by gonadotropin-releasing hormone analogues. Thyroid 2003;13:815-8.

8. Morita S, Ueda Y. Graves' disease associated with goserelin acetate. Acta Med Nagasaki 2000;47:79-80.
9. van Bon AC, Wiersinga WM. Goserelin-induced transient thyrotoxicosis in a hypothyroid woman on L-thyroxine replacement. Neth J Med 2008;66:256-8.

10. Eyal O, Rose SR. Autoimmune thyroiditis during leuprolide acetate treatment. J Pediatr 2004;144:394-6.

11. Jacobson JD. Gonadotropin-releasing hormone: potential role in autoimmunity. Int Immunopharmacol 2001;1:107783.

12. Metcalfe W, Boulton-Jones JM. Exacerbation of lupus nephritis in association with leuprorelin injection for uterine leiomyoma. Nephrol Dial Transplant 1997;12:1699-700. 